\title{
Antropología
}

\section{Salud en las Prisiones: lo que hablan los trabajadores de enfermería}

\section{Health in Prisons: the speaking nursing workers}

\section{Saúde no Sistema Penitenciário: o que falam os trabalhadores de enfermagem}

\begin{abstract}
Fernanda de Jesus dos Santos'; Danielly Santos dos Anjos Cardoso²; Mércia Zeviani Brêda ${ }^{3}$;
\end{abstract}
Laís de Miranda Crispim Costa ${ }^{4}$

${ }^{1}$ Graduanda de Enfermagem da Universidade Federal de Alagoas - UFAL.

${ }^{2}$ Enfermeira, mestre em enfermagem, professora professora assistente da Escola de Enfermagem e Farmácia - ESENFAR da UFAL.

${ }^{3}$ Enfermeira, doutora em enfermagem, professora professora assistente da ESENFAR.

${ }^{4}$ Enfermeira, mestre em enfermagem, professora assistente da ESENFAR, doutoranda do Programa de Pós-graduação e Pesquisa da Escola Anna Nery da Universidade Federal do Rio de Janeiro.

Cómo citar este artículo en edición digital: Santos, F. J., Anjos, D.S.C., Brêda, M.Z. y Costa, L.M.C. (2015). Salud en las Prisiones: lo que hablan los trabajadores de enfermería. Cultura de los Cuidados (Edición digital), 19, 41.

Disponible en: http://dx.doi.org/10.14198/cuid.2015.41.14>

Correspondência: Fernanda de Jesus dos Santos. Rua Antônio Alves da Silva ${ }^{\circ}$ 302,

Santa Lúcia, Maceió- AL, CEP: 57082-630. Tel: (82) 88913886

Correo electrónico: nanda.enferm@gmail.com

Recibido: 17/11//2014; Aceptado: 13/02/2015

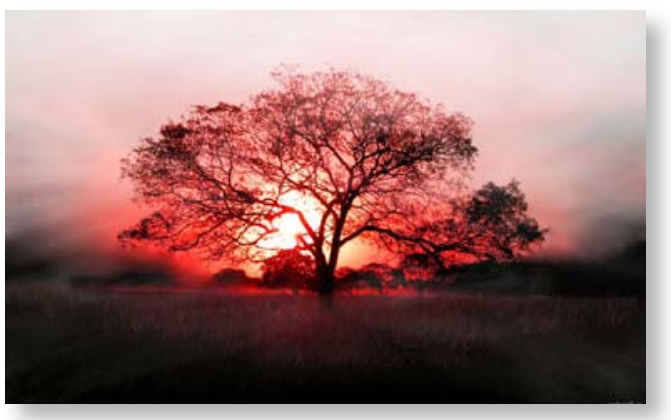

ABSTRACT

Objective: To analyze the health care provided to persons under confinement in the penitentiary system in the view of nursing.

Methodology: An exploratory study, a qualitative approach to analyze the discussion of participants, from the guiding question: How do the nursing staff perceive the health care offered in the prison system? Data collection was performed through recorded inter- views with the signing of terms of free and informed consent, conducted in April 2014, with 21 nursing staff of the penitentiary complex Maceió-AL, as approved by the Ethics Committee and research Platform UFAL via Brazil, and by CAAE No 25016814.6.0000.5013, receiving assent to its publication as protocol 560 840. Results: From the analysis of the interviews, three categories emerged: Many difficulties, some privileges; Stress, fear and involvement; Institutional force-health attention.

Conclusion: This study contributes to the knowledge on the topic in question, and the debate on health care offered in the prison system in order to improve service delivery and care persons deprived of liberty.

Keywords: prison; health care; nursing; public health. 


\section{RESUMEN}

Objetivo: Analizar la asistencia sanitaria prestada a las personas menores de confinamiento en el sistema penitenciario en la vista de la enfermería.

Metodología: Estudio exploratorio, un enfoque cualitativo para analizar la discusión de los participantes, a partir de la pregunta orientadora: ¿De qué manera el personal de enfermería percibe la asistencia sanitaria ofrecida en el sistema penitenciario? La recolección de datos se realizó a través de entrevistas grabadas con la firma de los términos de consentimiento libre e informado, realizado en abril de 2014, con 21 miembros del personal de enfermería del complejo penitenciario de Maceió-AL, tal como fue aprobado por el Comité de Ética y Investigación Plataforma UFAL vía Brasil y por el CAAE No 25016814.6.0000.5013, recibiendo consentimiento a la publicación del mismo Protocolo 560 840. Resultados: En el análisis de las entrevistas, surgieron tres categorías: Muchas dificultades, algunos privilegios; El estrés, el miedo y la participación; La atención de la salud de fuerza institucional.

Conclusión: Este estudio contribuye al conocimiento sobre el tema en cuestión, y el debate sobre la atención de salud ofrecida en el sistema penitenciario a fin de mejorar la prestación de servicios y atención las personas privadas de libertad.

Palabras clave: la cárcel; cuidado de la salud; enfermería; la salud pública.

\section{RESUMO}

Objetivo: analisar a atenção em saúde prestada às pessoas em regime de reclusão no sistema penitenciário na visão dos trabalhadores de enfermagem.

Metodologia: estudo exploratório, de abordagem qualitativa, com análise da discussão dos participantes, a partir da questão norteadora: De que forma os trabalhadores de enfermagem percebem a atenção em saúde ofertada no sistema penitenciário? A coleta de dados foi realizada por meio de entrevistas gravadas, com assinatura dos termos de consentimentos livre e esclarecido, realizadas no mês de abril de 2014, com 21 trabalhadores de enfermagem do complexo penitenciário de Maceió-AL, conforme aprovação do Comitê de Ética e Pesquisa da UFAL via Plataforma Brasil, e mediante CAAE no 25016814.6.0000.5013, recebendo parecer favorável para sua publicação conforme protocolo $\mathrm{n}^{\circ} 560.840$. Resultados: a partir das análises das entrevistas, emergiram as três categorias: Muitas dificuldades, alguns privilégios; Tensão, medo e envolvimento; Força institucional x Atenção em saúde.

Conclusão: $O$ estudo contribui para a construção do conhecimento sobre a temática em questão, e a reflexão sobre a atenção em saúde ofertada no Sistema Penitenciário com vistas à melhor prestação dos serviços e cuidados as pessoas privadas de liberdade.

Descritores: penitenciárias; atenção à saúde; enfermagem; saúde pública.

\section{INTRODUÇÃO}

Dados do Ministério da Justiça mostram que cerca de 520 mil pessoas vivem privadas de sua liberdade nos sistemas penitenciários do Brasil em 1.771 estabelecimentos penais, onde haveria vaga para menos de 310 mil, segundo o Sistema Integrado de Informações Penitenciárias (Infopen), ou seja, há uma superlotação dessa população específica o que resulta não só numa sobrecarga do sistema, mas no aumento da condição de risco e vulnerabilidade em que estão submetidos. (Dominguez, 2012).

Conforme Assis (2007), aproximadamente 95\% da população penitenciária brasileira é 


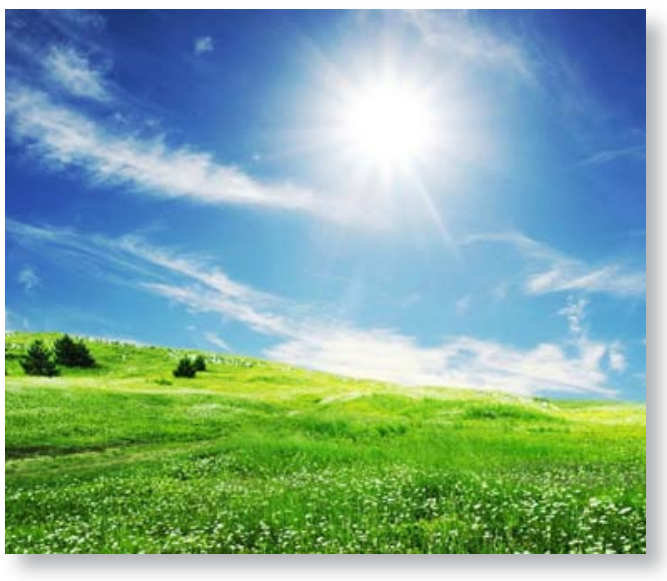

oriunda das classes dos excluídos socialmente, ou seja, pobres, negros, analfabetos e desempregados, que, de certa forma, são "empurrados" ao crime por não terem tido melhores oportunidades.

Mediante a superlotação das celas, a precariedade e o alto grau de insalubridade, tornam as prisões um ambiente propício à difusão de doenças. Além dos fatores estruturais, a alimentação deteriorada, a falta de higiene, o sedentarismo, o uso de drogas, a precária assistência médica e a violência incontida permeiam as relações nas unidades penitenciárias, como também contribuem para os problemas de saúde. (Assis, 2007; Carvalho et al, 2006; Savazzoni, 2010).

Independente da natureza de sua transgressão, este público mantêm o direito de usufruir dos diversos padrões de assistência à saúde, tais como ações preventivas, de cura e de reabilitação, atendimento médico, de enfermagem, odontológico, farmacêutico e psicológico, porque apesar de se encontrarem privados de liberdade, ainda mantêm preservados os demais direitos humanos inerentes à sua cidadania.

Embasado nas ideias democráticas da Constituição Federal (CF), que a "saúde é um direito de todos e um dever do Estado" (Brasil, 1988), o Ministério da Saúde em ação inte- grada com o Ministério da Justiça elaborou o Plano Nacional de Saúde no Sistema Penitenciário (PNSSP) através da Portaria Interministerial no 1.777, de 09 de setembro de 2003 que prevê a inclusão da população penitenciária no SUS, garantindo que o direito à cidadania se efetive na perspectiva dos direitos humanos, como também que se criem estruturas de unidades básicas de saúde nos estabelecimentos prisionais (Brasil, 2003).

\section{Conforme Souza (2006, p. 16)}

"a enfermagem pode contribuir para o resgate de uma condição de vida digna das pessoas, tanto do ponto de vista biológico, quanto social e psicológico proporcionando conforto e bem estar, minimizando iniciativas que estimulem a discriminação ou o preconceito, e ainda respeitando os princípios éticos e legais, com vistas a resgatar o sentido da existência humana".

Embora os cuidados de enfermagem sejam semelhantes aos de uma unidade hospitalar extramuros, o fato do ambiente extra-hospitalar não ser a casa ou a rua, mas uma penitenciária confere aos profissionais de enfermagem diversas mudanças, seja nas atitudes, posturas ou sentimentos, durante a prática assistencial (Souza, Passos, 2008; Cardoso, Araújo, 2013).

Estudo realizado por Eugênio (2012) evidenciou que apesar das atividades desenvolvidas pelo trabalhador de saúde nas unidades prisionais não se diferenciarem das impostas pela Lei do Exercício Profissional e da realidade extramuros, existe um conflito de sentimentos positivo e negativo na prática diária da profissão na unidade prisional, o qual se justifica pelo próprio sentimento despertado inerente a profissão e/ou ainda pelo tipo de clientela e ambiente envolvido na assistência.

Diante do que foi exposto em linhas gerais 
é que este estudo busca elucidar a seguinte questão norteadora: De que forma os trabalhadores de enfermagem percebem a atenção em saúde ofertada no sistema penitenciário? Para tanto se traçou o objetivo geral: Analisar a atenção em saúde prestada às pessoas em regime de reclusão no sistema penitenciário na visão dos trabalhadores de enfermagem.

\section{METODOLOGIA}

Trata-se de uma pesquisa qualitativa de abordagem exploratória com apreciação das falas narrativas. O método qualitativo enfatiza as especificidades de um problema em termos de sua origem e da sua razão de ser, fazendo uma relação direta entre a realidade e o sujeito, ou seja, uma ligação entre o mundo objetivo e a subjetividade do sujeito (Silva, 2005).

A finalidade das pesquisas exploratórias, segundo Gil (2008) é a de proporcionar um maior conhecimento para o pesquisador acerca do assunto, a fim de que esse possa formular problemas mais precisos ou criar hipóteses que possam contribuir em estudos posteriores. Utiliza-se do levantamento bibliográfico, entrevistas com pessoas que tem experiência prática com a problemática em questão e a análise de exemplos que estimulem a compreensão.

$\mathrm{O}$ estudo ocorreu em quatro unidades carcerárias localizadas no Complexo Penitenciário de Maceió e os participantes foram os trabalhadores que integram a equipe de enfermagem em unidades carcerárias masculinas, totalizando 21 profissionais, dentre eles: 04 enfermeiros, 16 técnicos e 01 auxiliar de enfermagem. Para seu recrutamento foram estabelecidos alguns critérios: estar o funcionário trabalhando na unidade à época do início da pesquisa e a aceitação em participar do estudo. Foram excluídos os que não aceitaram participar do estudo e aqueles que estavam de férias.
O estudo está de acordo com a Resolução no 466, de 12 de dezembro de 2012, do Ministério da Saúde, que trata da ética nas pesquisas envolvendo seres humanos. Inicialmente, foi encaminhado o projeto desta pesquisa para o Comitê de Ética e Pesquisa da Universidade Federal de Alagoas via Plataforma Brasil, com CAAE n 25016814.6.0000.5013. Após análise, foi recebido o parecer favorável no 560.840 , onde somente após aprovação deste e autorização da Diretoria das Unidades Penitenciárias iniciou-se a coleta de dados.

As entrevistas ocorreram por meio de um agendamento prévio junto a Diretoria das Unidades Penitenciárias (DUP), que iam de acordo com a disponibilidade do serviço e dos profissionais. Os participantes foram abordados no posto de enfermagem de cada unidade penitenciária, onde foram convidados a participar, sendo-lhes explicada a importância da pesquisa. Após concordância os voluntários assinaram o Termo de Consentimento Livre e Esclarecido, permitindo coletar os dados através de uma entrevista semiestruturada gravada.

A coleta das informações aconteceu no mês de abril de 2014. A entrevista semiestruturada obedece a um roteiro que é utilizado pelo pesquisador, servindo de apoio na sequência das questões, a fim de facilitar a abordagem e assegurar que seus pressupostos sejam abordados na conversa, permitindo também, que novas perguntas sejam introduzidas para que haja uma abertura do campo de explanação do entrevistado ou um aprofundamento do nível de informações ou opiniões (Minayo, 2010).

Os dados obtidos, a partir das entrevistas semiestruturadas, foram inicialmente transcritos na íntegra. Na transcrição foi preservada a fala dos participantes os quais foram identificados por códigos alfanuméricos, em que a letra E significa enfermeiro, a sigla TE, 
técnico de enfermagem e a sigla $\mathrm{AE}$, auxiliar de enfermagem, e os números seguem a ordem de ocorrência das entrevistas.

Foi realizada uma leitura atenta e apurada sobre todo material, e as informações classificadas qualitativamente, sendo as classes que emergiram categorizadas, segundo análise temática de conteúdo. Com essa técnica, segundo Gomes (2002) é possível investigar o que está por trás dos conteúdos, indo além das aparências do que está sendo estudado.

Conforme Bardin (2011) a análise de conteúdo ocorre a partir de três fases básicas:

$1^{\text {a }}$ Fase: Pré-análise - Corresponde ao período de sistematizar as ideias iniciais, preparando para a análise propriamente dita. É realizada através de leituras flutuantes, e composição do corpus, o qual corresponde ao conjunto de documentos necessários aos procedimentos analíticos.

2a Fase: Exploração do material ou codificação - Após leitura e exploração de todo o material, os dados são codificados e categorizados, em função das quais o conteúdo da análise será organizado. Dessa forma, o processo de categorização consiste na redução do texto às palavras e expressões significativas.

$3^{\text {a }}$ Fase: Tratamento dos resultados obtidos e interpretação - Corresponde a análise essencialmente temática, resultando em dimensões, as quais serão sequencialmente analisadas. $\mathrm{O}$ intuito é de tornar os resultados significativos e válidos para o estudo.

\section{RESULTADOS E DISCUSSÃO}

Dos 21 trabalhadores de enfermagem entrevistados, 16 eram do sexo feminino $(76,2 \%)$. Com relação à faixa etária: 08 possuíam entre 25 a 35 anos; 03 possuíam entre 36 a 45 anos; e 10 entre 46 a 56 anos. O tempo de atuação na instituição penitenciária variava: menor que 2 anos ( 7 trabalhadores), entre 2 a 3 anos (6),e maior que 3 anos (8). Os resultados apontaram três categorias conceituais: Muitas dificuldades, alguns privilégios; Tensão, medo e envolvimento; Força institucional x Atenção em saúde.

\section{Muitas dificuldades, alguns privilégios}

O sistema penitenciário vive num processo de transição do caráter punitivo ao ressocializador, porém encontra alguns entraves devido às condições precárias do sistema penal, que acaba refletindo também, na vulnerabilidade da população penitenciária a diversas patologias. Dessa forma, alerta-se para uma maior atenção seja demandada a este público através de ações positivas que incluam a disponibilidade de serviços e recursos, sob a ótica do modelo assistencial que melhor atenda as suas necessidades.

Conforme Silva Júnior e Alves (2007) o modelo assistencial se refere à forma como são organizadas as ações de atenção em saúde, envolvendo aspectos tecnológicos e assistenciais (Paim, 2001), utilizados no processo de trabalho de modo a intervir sobre os problemas e necessidades sociais de saúde.

$\mathrm{O}$ atual modelo vigente no país estrutura-se na visão negativa de saúde, vinculando esse à doença e à morte, ou seja, há predominância de caráter assistencialista e curativo. Nesse modelo, ocorre grande fragmentação na atuação dos profissionais de saúde, em alguns casos, precarizando as relações de trabalho.

De acordo com Gil (2005) não é tarefa fácil conseguir profissionais aptos a trabalharem na perspectiva do novo modelo, dentro da visão de promoção da saúde, pois (Cutolo, 2001), a problemática encontra-se no modelo de formação destes profissionais: hospitalocêntrico, biologicista, fragmentado. Nesse sentido, as 


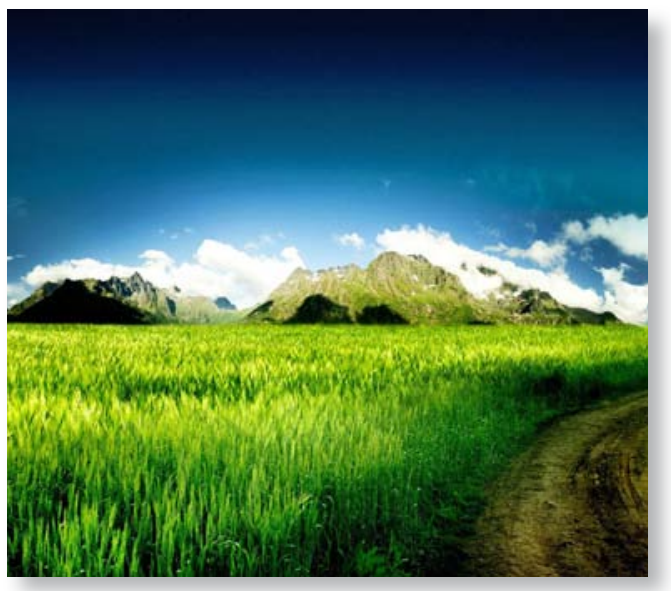

respostas para os problemas de saúde passam a se estruturar na atenção médica e medicamentos, reduzindo a atenção em saúde na oferta desses serviços.

"Eu posso dizer como profissional da assistência que é deficiente, devido a falta de medicamentos, poucos profissionais médico para dar um suporte maior". (TE14)

Dessa forma, a percepção do profissional de enfermagem a respeito da atenção em saúde está, como observado na maioria das falas, atrelada as dificuldades presentes no serviço de saúde do sistema penitenciário, os quais foram identificados como na falta de medicação e na ausência de um profissional médico todos os dias. A carência de medicamentos foi destacada na totalidade das unidades penitenciárias em estudo, situação esta resolvida, com a compra do medicamento pela família.

"não tem como você dar assistência que deveria dar a eles por causa da falta de condições de trabalho. Falta muito material". (TE3)

"o atendimento aqui é muito bom, claro que as medicações: tem umas que faltam, mas ai gente comunica a assistente social que comunica a família, e a família traz”. (TE6)

$\mathrm{O}$ que se observa é que, o Estado não consegue cumprir o determinado na Lei de Execuções Penais, e consequentemente, os indiví- duos reclusos tem sua saúde debilitada devido as péssimas condições, e conforme Capitani (2012) chegando a morrer por falta de atendimento médico, medicação e por falta de uma atividade preventiva.

Quanto ao transporte desses pacientes para tratamento externo e urgência, este só é permitido mediante a presença da escolta policial, visualizada pelos participantes como outra precariedade do sistema. Acrescentam ainda que, a presença do médico todos os dias na unidade penitenciária reduziria bastante as saídas 'desnecessárias'. Chama a atenção que, a escolta que dar suporte a saúde é a mesma que sai em missões, ou seja, quando ocorre alguma intercorrência dentro do complexo penitenciário que necessita de transferência, esta escolta muitas vezes não se encontra disponível.

"quando alguns presos necessitam de serem removidos com destino a uma unidade básica de saúde temos a deficiência com relação ao transporte desse preso, porque tem que haver uma escolta pra dar segurança ao profissional, garantir a integridade física do preso e também dos profissionais que irão atendê-lo na unidade que vamos encaminhá-lo". (TE14)

"A dificuldade é a escolta pra sair que nem sempre tem". (TE7)

"Quando não tem o médico do dia, a gente leva pra alguma unidade de pronto-socorro, se for urgência e emergência”. (TE15)

No que concerne a atuação do profissional de enfermagem no sistema penal, percebe-se que estes têm suas ações limitadas, respondendo as demandas trazidas pelo agente penitenciário, que fica responsável pela condução do recluso ao serviço de saúde, a partir da solicitação deste. Este dado corrobora com os achados de Cavalcanti (2012) que ainda acrescenta que é o agente penitenciário que realiza a triagem das necessidades de saúde dos reclusos 
nas celas, para então encaminhá-los a unidade de saúde.

"Geralmente eles [presos] chamam o agente". (TE16)

"A única dificuldade pra chegar até a gente é que, antes de chegar até a gente eles [presos] têm que ter o acompanhamento dos agentes penitenciários. A gente não vai até a cela pegar eles e trazer. Eles chamam o agente penitenciário, e assim que eles trazem, ele[preso] têm todo $o$ atendimento necessário”. (E4)

Da mesma forma que o agente penitenciário atua facilitando o acesso desse paciente/ recluso à saúde, eles também podem dificultar, pois, na maioria das vezes, são eles quem julgam a necessidade de atendimento a partir do pedido do indivíduo (Diuana et al, 2008). Dessa forma fica evidente a função diferenciada executada pelos agentes penitenciários, no que diz respeito à acessibilidade da pessoa reclusa à saúde, situação também percebida neste estudo, através da demora do agente na retirada destes para atendimento.

"Muitas vezes demoram a tirar e o paciente fica lá com dor..." (E4)

"Às vezes eles demoram um pouco mais, mas sempre tiram. Nunca se omitiram não... Sempre tiraram. Às vezes mais rápido, às vezes mais lento." (E4)

Apesar da ausência do médico representar um fator negativo para a prática de atenção em saúde, o sistema penitenciário conta com uma equipe multidisciplinar presente todos os dias a disposição dos pacientes/reclusos, e portanto, sendo apontado como uma facilidade para a prática de atenção em saúde, dados estes que divergem com os encontrados por Assunção (2010), no qual a ausência de uma equipe multiprofissional tornava-se um obstáculo para a prestação da assistência em saúde.

"A facilidade é uma equipe multidisciplinar que ele encontra facilmente aqui no sistema. Todo reeducando tem direito aqui, de assistência de enfermagem, assistência de nutrição, ele tem assistência de dentista, psicólogo, assistente social e médico. Então ele tem uma equipe multidisciplinar envolvida pra cuidar da saúde dele. A maior dificuldade na verdade é o médico, que só vem uma vez na semana”. (E4)

Apesar de estarem privados de sua liberdade, os reclusos mantém assegurados os demais direitos, dentre eles, o direito a saúde. Dessa forma, a disponibilidade de uma equipe de saúde não seria mais que uma facilidade, mas sim um direito garantido, já que tantos outros lhe são retidos. Outro ponto que chama a atenção são os questionamentos levantados pelos profissionais quanto ao atendimento externo, pela rapidez e prioridade. Neste ínterim, Leal e Lopes (2005) trazem que a prioridade de atendimento ambulatorial decorre em não expor os demais pacientes ao risco de violência entre reclusos e policiais, já que este último mantém-se munido de forte armamento.

"assim que a gente chega em qualquer unidade ele tem prioridade. Então, ele passa na frente de idoso, passa na frente de criança." (TE13)

Mesmo diante de uma situação em que haja choque de valores éticos e morais, o profissional de saúde deve se posicionar como aquele que presta cuidados independente a natureza daquele que se encontra sob seus cuidados, ou seja, livre de julgamentos.

\section{Tensão, medo e envolvimento}

O trabalho numa unidade penitenciária é permeado por um clima de instabilidade e imprevisibilidade do que pode acontecer. Conforme Santos (2012), o recluso está sempre buscando meios de conseguir sua liberdade novamente, seja através de uma tentativa 
de suborno de algum funcionário, ou uma rebelião. Este risco de que algo possa ameaçar a vida da equipe, traduz-se na tensão do ambiente, como observado nos depoimentos abaixo, onde a qualquer movimentação ou barulho os profissionais ficam assustados.

"A gente percebe que os profissionais eles tentam manter aquela calma, aquilo tudo, mas qualquer barulho que der aqui dentro, todo mundo já fica tenso". (E1)

Outro ponto, diz respeito à preocupação do trabalhador da enfermagem com sua integridade física, no qual suas atividades sempre ocorrem na presença do agente penitenciário e sob um estado de alerta. A figura do agente penitenciário representa um papel protetor e de segurança. Portanto, a atenção em saúde, de acordo com Santos (2012) traduz-se em não se descuidar, prestando assistência prevendo os eventos que possam se converter em situação de perigo, onde um simples instrumento sob posse dos reclusos possa se transformar numa arma. Como ilustrado nas falas seguintes:

"Você tem que está sempre com um pé atrás, sempre cercado de vários agentes porque a gente não sabe qual vai ser a reação deles." (E3)

"É de eles virem pra enfermaria com algum tipo de arma. Às vezes eles fazem de qualquer pedacinho, até do barbeador eles fazem uma arma, então isso é risco". (TE1)

Santos, Souza, Santos (2006) ainda reforçam dizendo que, tanto reclusos quanto profissionais compartilham sentimentos que podem favorecer ou prejudicar o cuidado, dentre tais sentimentos, o medo que os profissionais sentem durante o atendimento a este público, que por ser algo próprio do ser humano, acontece independente do querer. Contrastando com este achado, no presente estudo, verifica-se por meio das falas abaixo, que os trabalhadores de enfermagem sentem-se seguros em suas práti- cas diárias, atrelando esta segurança ao tempo de serviço neste ambiente, fato este que entra de acordo com os resultados encontrados por Eugênio (2012), no qual argumenta que reclusos mantêm o respeito, pois veem na equipe de enfermagem profissionais envolvidos na preservação da saúde.

"No início foi difícil. Não queria muita aproximação, por conta mais do medo". (TE11)

"Eu perdi o medo de trabalhar com reeducandos. Não tenho mais medo de jeito nenhum. Pelo tempo, são sete anos já”. (TE15)

Diferente dos achados no estudo de Christoff (2007), no qual os técnicos de enfermagem manifestavam curiosidade a respeito das histórias de delito daqueles que ali se encontra, a equipe de enfermagem em questão destacou que seu relacionamento com os presos é estritamente profissional, baseada no respeito, com ética e humanização no atendimento. Ou seja, não procuravam saber os antecedentes criminais das pessoas a quem estavam prestando cuidados, dados estes que também corroboram com o estudo de Santos (2012).

"Eu não olho nada do crime deles: se eles mataram, se foram acusados, se tiveram porte de arma ou não. Eu não olho isso. Eu olho apenas o cuidado". (E1)

"Não estou aqui pra julgar o preso, não importa o que ele fez ou o que ele deixou de fazer. Eu vejo o preso como um paciente que necessita de um atendimento, então a minha relação é simplesmente profissional. Ele é o paciente, e eu estou aqui para dar assistência de enfermagem". (TE14)

Para a assistência em saúde é imprescindível o levantamento sistematizado dos dados da pessoa, pois permite ao profissional de saúde identificar problemas, realizar diagnóstico, planejar e implementar sua assistência (Santos, Veiga, Andrade, 2011). Dessa forma, como 
prestar uma assistência mais humanizada sem anamnese? Por meio da coleta de dados é possível conhecer os indivíduos e planejar uma assistência não só curativa, mas também preventiva, servindo de método de acompanhamento e avaliação (Santos, Veiga, Andrade, 2011).

\section{Força institucional x Atenção em saúde}

Formalmente o agente penitenciário é o profissional responsável pela ressocialização. No entanto, o perfil deste profissional diante de sua atuação perpassa por uma série de questões que vão desde a operacionalização comportamental de suas atribuições na rotina de trabalho a dilemas relacionais, conceituais e identitários (Andrade, Silva, Figueiró, 2013).

Diante disso, identifica-se que a presença do agente penitenciário torna-se primordial para a assistência em saúde devido à situação de periculosidade que o ambiente impõe. Por outro lado, a equipe de saúde inserida nesse contexto, com destaque o profissional de enfermagem, considera a presença do agente penitenciário uma limitação para a autonomia no desempenho de suas ações (Souza, Passos, 2008), que necessita a todo o momento, dividir seu espaço de cuidado com o agente.

Dessa forma, percebe-se que a relação de trabalho entre agente penitenciário e enfermagem é convergente, onde segurança e saúde estão em prioridades diferentes. Contudo, verifica-se no presente trabalho dados semelhantes em literatura, quanto à dependência da equipe de enfermagem ao agente na prestação do cuidado (Santos, 2012; Mariath, Rita, 2010). A presença do agente penitenciário é compreendida como uma necessidade para as atividades desempenhadas pelos profissionais de saúde.

"a dificuldade é que eu preciso de agentes penitenciários, tanto pra trazer eles até a enfermaria como pra que eu consiga chegar até os módulos de prisão". (E1)

"a gente[profissional de enfermagem] só pode ser acompanhada no raio com o agente. Quando tem a gente vai. Quando não, a gente aguarda”. (TE2)

Outra questão marcante, que pode ser observado por meio do depoimento acima é a carência na quantidade de agentes penitenciários disponíveis, que por vezes acaba interferindo na qualidade da assistência prestada, onde o cuidado é "adiado".

"a gente [profissional de enfermagem] dava a lista toda manhã e nada de tirarem pra atender, porque tava pouco o contingente de agente... então era muito complicado de prestar assistência da forma adequada”. (E3)

Uma melhoria do serviço de atenção à saúde dos reclusos foi percebida com o surgimento de uma nova classe de trabalhadores na unidade penitenciária, o surgimento do monitor, que atua facilitando o acesso dos reclusos aos serviços de saúde, pois devido ao quantitativo insuficiente de agentes penitenciários acabavam por prejudicar a assistência.

"hoje tem os monitores que nos ajudam muito na retirada dos presos para o atendimento. Antigamente, como tinha um déficit negativo em relação a agente penitenciário, ai dificultava muito nosso atendimento". (E2)

Num estudo realizado por Diuana et al (2008) observou-se que a relação entre agente penitenciário e recluso baseava-se numa estratégia de defesa das identidades, em que encaminhá-lo ao serviço de saúde era motivo de deboche. Ademais, o cuidado surge como sinal de rebaixamento e submissão, inadmissível para a manutenção da imagem de "força" e "poder" que impera sobre o agente penitenciário. Quando se trata da relação agente penitenciário e profissional de enfermagem, 
por vezes acabam esbarrando em princípios e valores sociais e que, conforme citado por um dos entrevistados no estudo de Souza (2006), ocorre um "desencontro de propósitos", fato este também percebido em um dos depoimentos deste estudo.

"quanto a relação com os agentes as vezes é meio complicado porque eles não entendem que o preso, que o custodiado, ele também é um ser humano e também precisa de assistência de saúde. Eles acham que eles estão ali pra tentar pagar um crime e que eles não deveriam ter tanta assistência de saúde como eles têm." (E1)

A característica do sistema penitenciário é marcado pela presença do agente de segurança, indispensável a qualquer atividade que irá se desenvolver dentro dessa instituição, devido a periculosidade instaurada pelo os que lá se encontram. No entanto, fica evidente que a concepção destes profissionais sobre a finalidade de uma instituição penitenciária refletirá diretamente no seu dia a dia no trabalho, contribuindo ou prejudicando para a reinserção da pessoa reclusa a sociedade.

\section{CONCLUSÃO}

A situação de cárcere traz uma série de impasses que tornam ainda mais complexo o acesso à saúde dos indivíduos reclusos. Na realidade local, percebe-se que a atenção à saúde da população que se encontra em unidades penitenciárias ainda possui um olhar reducionista, na medida em que as ações desenvolvidas limitam-se àquelas voltadas ao modelo curativista.

As ações de saúde desenvolvidas no sistema penitenciário ocorrem por meio do processo queixa-conduta, no qual ao agente penitenciário fica imputado a responsabilidade quanto à acessibilidade dos reclusos aos serviços de saúde, e que, de certa forma, eles que acabam julgando quem necessita ou não de

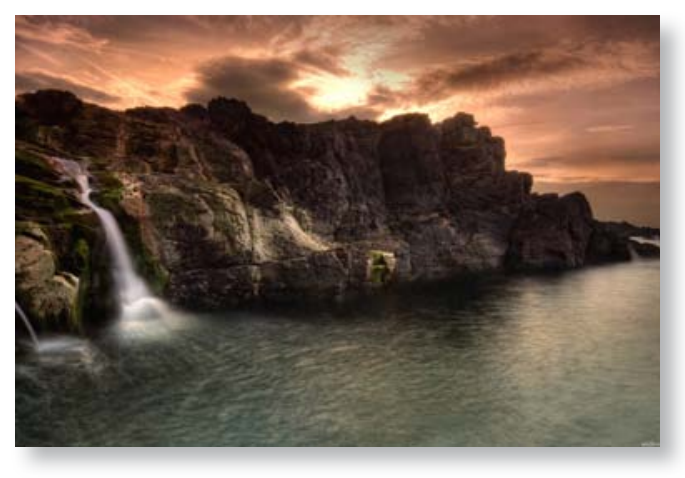

atendimento, ficando evidente também, que o serviço de saúde atua respondendo as demandas trazidas por este profissionais.

O sistema penitenciário é tido como sinônimo de periculosidade, tanto pelas pessoas que ali se encontram como pelo o ambiente onde são desenvolvidas as relações. Por meio deste estudo foi constatado que os profissionais de enfermagem que possuem mais tempo de serviço no sistema penal sentem-se seguros durante suas atividades, em contrapartida, há aqueles que ainda se mantêm tensos mesmo rodeados de guardas e armamentos.

O modo de organização da instituição penitenciária é baseada na segurança, tendo o agente penitenciário como o protagonista. Sua presença é imprescindível para todas as atividades desenvolvidas neste ambiente, e na área da saúde este fato é de grande relevância, pois o trabalhador da saúde tem suas atividades limitadas a este profissional, pois depende de sua presença e disponibilidade.

Portanto, os resultados possibilitaram conhecer a realidade frente à atenção em saúde prestada às pessoas em regime de reclusão e apontam caminhos que precisam ser percorridos, para que uma assistência de qualidade seja demandada a esta população, mediante a garantia de direitos legalmente constituídos e a ampliação do acesso aos meios e serviços de promoção, prevenção, assistência e recuperação da saúde. 


\section{REFERÊNCIAS}

- Andrade, J. M. S., Silva, A. K. L. y Figueiró, R. A. (2013). O sistema prisional e o trabalho do agente penitenciário: reflexões sobre o trabalho no cárcere. In R.A. Figueiró., E.S.S. Figueiró. y Minchoni, T. (Comps.) Saúde e sistema prisional: impasses e possibilidades no Rio Grande do Norte. Natal: Edunp. Disponível em: http://edunp.unp. br/pdf/SistemaPrisional.pdf.

- Assis, R. D. (2007). A realidade atual do sistema penitenciário brasileiro. Revista CEJ, 11(39), 74-78. Disponível https://www2.cjf.jus.br/ojs2/index.php/revcej/article/ viewFile/949/1122.

- Assunção, C. H. V. (2010). A saúde da mulher: a situação das encarceradas do Presídio Feminino de Florianópolis. Monografia (Bacharelado em Serviço Social). Florianópolis: Universidade Federal de Santa Catarina- UFSC.

- Bardin, L. (2011). Análise de conteúdo. Lisboa: Edições 70.

- Brasil. (1988). Constituição 1988. Constituição da República Federativa do Brasil. Brasília, DF: Senado Federal. Disponível http://www.planalto.gov.br/ccivil_03/constituicao/constituicao.htm.

- Brasil. (2003). Portaria Interministerial $n^{\circ} 1777$, de 09 de setembro de 2003. Dispõe sobre o Plano Nacional de Saúde no Sistema Penitenciário. Brasília. Disponível http://www.saude.mg.gov.br/images/documentos/Portaria_1777.pdf.

- Capitani, R. (2012). O meio ambiente prisional brasileiro e a saúde do preso: um estudo no Presídio Estadual de Bento Gonçalves. Dissertação (Mestrado)- Programa de Pós-Graduação em Direito. Universidade de Caxias do Sul.

- Cardoso, D. R. y Araújo, S. T. C. (2013). Enfermagem no sistema prisional: o significado da comunicação pelos sentidos do corpo. In: 17 SENPE- Seminário de Pesquisa em Enfermagem, 2013, Natal/ RN. O clássico e o emergente: desafios da pesquisa em enfermagem, Jun. Disponível http://www.abeneventos.com.br/anais_ senpe/17senpe/pdf/0055pr.pdf.

- Carvalho, A. L. et al. (2006).Perfil dos internos no sistema prisional do Rio de Janeiro: especificidades de gêne- ro no processo de exclusão social. Ciência Saúde Coletiva, 11(2), 461-71. Disponível http://www.scielo.br/pdf/ csc/v11n2/30433.pdf.

- Cavalcanti, V. M. (2012). Dupla privação: a realidade de apenados com deficiência física em presídios na Paraíba. Trabalho de Conclusão de Curso (Graduação em Enfermagem) - Universidade Estadual da Paraíba.

- Christoff, M. U. (2007). Saúde e cárcere: micro-unidades penitenciárias de atendimento hospitalar, no Rio Grande do Sul. Tese (Doutorado)- Programa de Pós-Graduação em Sociologia. Porto Alegre: Universidade Federal do Rio Grande do Sul.

- Cutolo, L. R. A. (2001). Estilo de pensamento em educação médica - um estudo do currículo do curso de graduação em medicina da UFSC. Tese (Doutorado em Educação). Florianópolis: Universidade Federal de Santa Catarina.

- Diuana, V. et al. (2008). Saúde em prisões: representações e práticas dos agentes de segurança penitenciária no Rio de Janeiro, Brasil. Cad. Saúde Pública, 24(8), 1887-1896. Disponível http://www.scielo.br/pdf/csp/v24n8/17.pdf.

- Dominguez, B. (2012). Uma política para garantir o direito à saúde no sistema prisional. Revista Radis, 118 . Disponível http://www6.ensp.fiocruz.br/radis/revista-radis/118/reportagens/uma-politica-para-garantir-o-direito-saude-no-sistema-prisional.

- Eugênio, M. R. (2012). A práxis do profissional enfermeiro no sistema penitenciário. Monografia (Graduação em Enfermagem). Cascavel, Faculdade Assis Gurgacz- FAG.

- Gil, A.C. (2008). Métodos e técnicas de pesquisa social. São Paulo: Atlas.

- Gil, C. R. R. (2005). Formação de recursos humanos em saúde da família: paradoxos e perspectivas. Cadernos de Saúde Pública, 21(2), Disponível http://www.scielo.br/ $\mathrm{pdf} / \mathrm{csp} / \mathrm{v} 21 \mathrm{n} 2 / 15$.pdf .

- Gomes, R. (2002). A análise de dados em pesquisa qualitativa. In M.C.S. Minayo, (Comp.) Pesquisa social: teoria, método e criatividade (PP.67-80). Petrópolis: Editora Vozes.

- Leal, S. M. C. y Lopes, M. J. M. (2005). A violência como objeto da assistência em um hospital de trauma: “o olhar" da enfermagem. Ciência \& Saúde Coletiva, 
10(2), 419-431. Disponível http://www.scielo.br/pdf/ csc/v10n2/a20v10n2.pdf .

- Mariath, C. R. y Rita, R. P. S. (2010). Polícia penitenciária: reflexo do sistema penal simbólico. Jus Navigandi, Teresina,15(2602). Disponível http://jus.com.br/artigos/17184.

- Minayo, M. C. S. (2010). Pesquisa Social: Teoria, método e criatividade. $29^{\mathrm{a}}$ ed. Rio de Janeiro: Ed. Vozes.

- Paim, J. S. (2001). Modelos assistenciais: reformulando o pensamento e incorporando a proteção e a promoção da saúde. Disponível http://repositorio.ufba.br/ri/handle/ ri/6168.

- Santos, F. S. (2012). Cuidados aprisionados: Repercussões na saúde do trabalhador de enfermagem do Hospital de Custódia e Tratamento Psiquiátrico. Dissertação (Mestrado Profissional Enfermagem Assistencial). Niterói: Universidade Federal Fluminense/ UFF.

- Santos, M. L. S. C., Souza, F. S. y Santos, C. V. S. C. (2006). As marcas da dupla exclusão: experiências da enfermagem com o psicótico infrator. Texto Contexto Enferm, 15, 79-87. Disponível http://www.scielo.br/pdf/tce/ v15nspe/v15nspea09.pdf.

- Santos, N., Veiga, P. y Andrade, R. (2011). Importância da anamnese e do exame físico para o cuidado do enfermeiro. Revista Brasileira de Enfermagem, 64(2), 355-
58. Disponível http://www.scielo.br/pdf/reben/v64n2/ a21v64n2.pdf .

- Savazzoni, S. A. (2010). Dignidade da pessoa humana e cumprimento de pena das pessoas com deficiência. Revista Eletrônica da Faculdade de Direito da PUC-SP 3. Disponível http://revistas.pucsp.br/index.php/red/article/view/5534/3949.

- Silva Júnior, A. y Alves, C. A. (2007). Modelos Assistenciais em Saúde: desafios e perspectivas. In M. V. G. C. Morosini y A. D. A. Corbo, (Comps.). Modelos de atenção e a saúde da família. Rio de Janeiro: EPSJV/Fiocruz: 27-41. Disponível http://www.uff.br/tcs2/images/stories/Arquivos/textos_gerais/4_Modelos_Assistenciais_ em_Sade_-_Aluisio_G._da_Silva_Jr_e_Carla_A._Alves. pdf.

- Silva, E.L. (2005). Metodologia da pesquisa e elaboração de dissertação. 4. ed. rev. atual. - Florianópolis: UFSC.

- Souza, M. O. S. (2006). A Prática de enfermagem no sistema penal: limites e possibilidades. Dissertação (Mestrado em Enfermagem). Rio de Janeiro: Universidade Federal do Estado do Rio de Janeiro.

S- ouza, M. O. S. y Passos, J. P. (2008). A prática de Enfermagem no Sistema Penal: limites e possibilidades. Esc. Anna Nery. Rev. Enferm, 12(3), 417-23. Disponível http://www.scielo.br/pdf/ean/v12n3/v12n3a04.pdf.

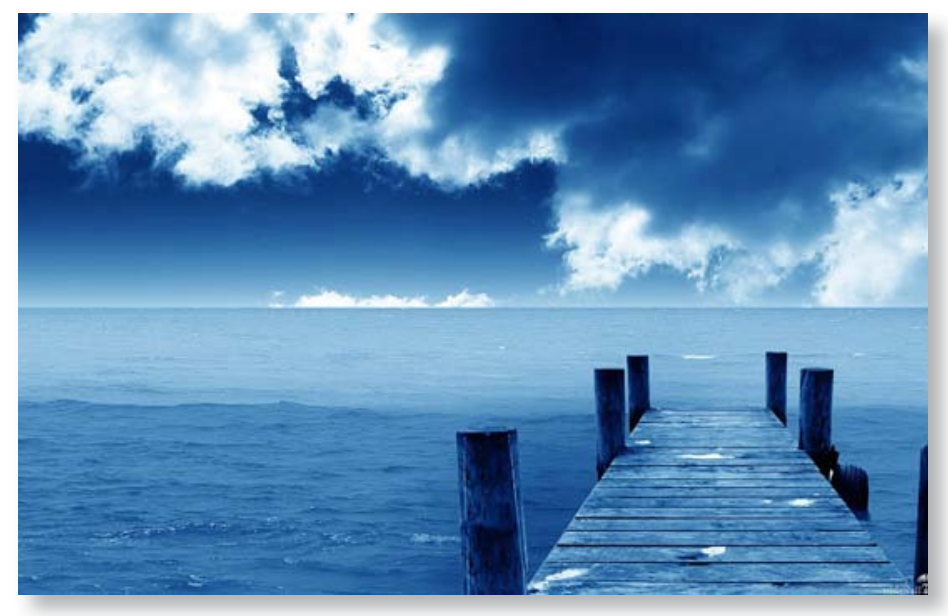

